\title{
Physicochemical Properties of Proteomic Ionic Liquids Matrices for MALDI-MS
}

Hani Nasser Abdelhamid*

Department of Chemistry, Assuit University, Assuit, 71515, Egypt

\begin{abstract}
Ionic liquid matrices (ILMs) have great contributions and showed high improvements for the protein analysis using matrix assisted laser desorption/ionization mass spectrometry (MALDI-MS). The physicochemical properties of these materials are important to understand the ILM performance and design the effective ILMs. The present study represented the relationships of the chemical structure and the physicochemical properties of ILMs. Different organic bases for two common organic matrices called 2,5-dihydroxy benzoic acid (DHB) and 3,5-dimethoxy-4-hydroxycinnamic acid (Sinapinic acid, SA) were calculated. The two series showed the same profile for molar refractivity, molar volume, Parachor, index of refraction, polarizability and surface tension. However, ionic liquids based on sinapinic acid showed higher values than DHB for all parameters except index of refraction and surface tension. These parameters may explain the high performance of SA-ILs for protein analysis compared to DHB-ILs. The present results are important for one who is looking for a new design of ILMs.
\end{abstract}

Keywords: Ionic liquids matrices; Matrix assisted laser desorption/ ionization; Molar of refractivity; Molar volume; Parachor; Index of refraction; Polarizability; Surface tension

\section{Introduction}

Matrix assisted laser desorption/ionization mass spectrometry (MALDI-MS) was recognized and was considered as remarkable analytical tool for the analysis of thermal-labile biomolecules [1]. The technique shared Nobel Prize in 2002 when Koichi Tanaka reported the laser desorption/ionization of protein from the surface of cobalt nanoparticles $(30 \mathrm{~nm})$ and developed methods for identification and structure analyses of biological macromolecules [2]. Thus, many methodologies were reported to improve the sensitivity, selectivity and advanced the technique [3]. The laser desorption/ionization process takes place by organic matrices $[1,4]$ or nanoparticles ( surface assisted laser desorption/ionization mass spectrometry, SALDI-MS) [5-10]. The major drawbacks of organic matrices are the presence of matrix ions in low mass range that cause ion suppression for the investigated analyte [11]

Room temperature ionic liquids matrices (RTILMs) have been used as a new type of matrices that assist laser desorption/ionization process for mass spectrometry [12-16]. They showed the advantages of the conventional matrices and offered new features such as low background for low molecular weight analysis, high sensitivity and showed high spectral quality. Furthermore, they served as solvent for ionic liquids assisted liquid-liquid micro extraction (ILA-LLME). They were used for mass spectrometry imaging and showed low toxic compared to the nanoparticles. These materials are cheap and offered dual functions such as matrices and solvent. The materials are easy for further modifications and have brilliant future in mass spectrometry. However, there is a limit information about the physico physical properties of these materials. The physical parameters studies of these materials are primary step for design of an effective matrix [17]. Computational methods were reported to explain the interaction changes outcome on moving from a molecular to an ionic liquid solvent [18].

In the present study, the parameters, such as molar refractivity, molar volume, Parachor, index of refraction, surface tension, density, polarizability and Ring Double Bond Equivalents $(R D B E)$, of two ionic liquids matrices (ILMs) were calculated. The effects of hydrophobic and hydrophilic properties of the cationic moieties were investigated. The data revealed dramatic changes for the two series. The pendant groups showed direct influential effect on the material properties. The present data are interested for design and to understand the performance of ILMs for MALDI-MS

\section{Computational of the Parameters}

Two different series of ionic liquids matrices (ILMs) were drawn and were investigated using computational software ACD/ChemSketch (Advanced Chemistry Development, Toronto, Ontario, Canada). Two different matrices were investigated called 2,5-dihydroxybenzoic acid (DHB) and 2,5-dimethoxy-4-hydroxy cinnamic acid (sinapinic acid, SA). To investigate the hydrophilicity of DHB and SA with pyridinium, 2-hydroxylpyridinium, 3-hydroxylpyridinium, 4-hydroxylpyridinium, 2,3-dihyroxylpyridinium, and 3,4-dihydroxylpyridinium, were investigated. For the hydrophobicity studies of DHB and SA with pyridinium, 2-methylpyridinium, 3-methylpyridinium, 4-methylpyridinium, 2,3-dimethyl pyridinium, 3,4-dimethylpyridinium, were investigated. The inductive effect of the heterocyclic ring was investigated using three different diazine rings called pyrimidium, pyridazinium, and pyrazinium. The chemical structures of the two series were shown in Figure 1 and 2.

\section{Results and Discussion}

Characterization and understand the physicochemical properties of ionic liquids matrices (ILMs) is paramount important for better performance of matrix assisted laser desorption/ionization mass

*Corresponding author: Hani Nasser Abdelhamid, Department of Chemistry, Assuit University, Assuit, 71515, Egypt, Tel: 00201279744643; Fax: 2342708 E-mail: hany.abdelhameed@science.au.edu.eg

Received January 12, 2016; Accepted February 10, 2016; Published February 17,2016

Citation: Abdelhamid HN (2016) Physicochemical Properties of Proteomic Ionic Liquids Matrices for MALDI-MS. J Data Mining Genomics Proteomics 7: 189 doi:10.4172/2153-0602.1000189

Copyright: (c) 2016 Abdelhamid HN. This is an open-access article distributed under the terms of the Creative Commons Attribution License, which permits unrestricted use, distribution, and reproduction in any medium, provided the original author and source are credited. 
spectrometry (MALDI-MS). The ionization of thermal labile biomolecules using direct laser irradiation causes fragmentation due to the high laser energy. Thus, matrices were used to transfer the laser energy softly. Ionic liquids matrices (ILMs) based on DHB and SA using different organic bases is shown in Figures 1 and 2, respectively. The two matrices were selected because the good performance for protein and peptide analysis. Two different pendant groups, hydrophilic ($\mathrm{OH})$ and hydrophobic $\left(-\mathrm{CH}_{3}\right)$, were investigated. The number of the pendant groups was varied to check the effect of the pendant groups in these parameters. The parameters, such as density, molar refractivity, molar volume, index of refractive, Parachor, surface tension, index of refraction, polarizability and RDBE, were investigated. The knowledge of these properties for different ionic liquids matrices (ILMs) is an important step for characterization and to understand the performance of ILMs-ALDI-MS

The chemical formula, compositions, density, Ring Double Bond Equivalents (RDBE), and mass of DHB-ILMs and SA-ILMs were tabulated in Tables 1 and 2, respectively. RDBE is calculated from valence values of elements contained in a formula. RDBE represents the number of bonds or rings. The value of DHB-ILMs and SA-ILMs are 8 and 9 , respectively. The high value of SA-ILMs implies high absorbance of laser energy compared to SA-ILMs.

The molar refractivity reflects the arrangements of the electron shells in the molecules and yields information about the electronic polarization of these species. These values are related to the hardcore volume of ionic liquids and it can be used to calculate the molar free volume. The molar refractivity of the two ionic liquids series was investigated as shown in Figure 3. The molar refractivity reflects the changes in the polarization due to deformation of the electron shells of the ionic liquids under the influence of the electric fields of the base moieties. Ionic liquids based on SA show higher values than those based on DHB. The two ionic liquids matrices (ILMs) show the same trends. Data indicate that the values of hydroxyl-base (hydrophilic cations) of both matrices are lower than hydrophobic. Presence of two nitrogen sites, i.e., pyrimidium, pyridazinium, and pyrazinium show the lowest values due to inductive effective of the diazine.

Polarizability is the molecules ability to be polarized. It implies information about the interactions possibilities with the other polarized molecules. Polarizabilities determine the dynamical response of a bound system to external fields. It is also important for the interactions with the laser radiations. It provides insight into the internal structures of ILMs. Thus, polarizability depends on the structure of ionic liquids matrices as shown in Figure 4. Quantum chemical calculations for imidazolium-based room temperature ionic liquids showed that the polarizability is isotropic dipolar polarizability or anisotropic dipolar polarizabilities [19]. Polarizability of the two series is different for the two series (Figure 4). The data show that SA-ILs is higher than DHB-ILs due to the presence of dimethoxy and hydroxyl groups. Furthermore, the double bond of the cinnamic acid moieties. It is important to stress that the polarizability require correlation because dipolarity and polarisability of each IL obviously contribute in different proportions to the value [20]. The values depend on the solvent properties and their interactions [21]. It has been reported that polarizability of RTILs reduce viscosity and increase ionic diffusion [19,22-24].

The molar volume is the volume occupied by one mole of ionic liquids matrices (ILMs). Large molar volume implies greater interaction with the analyte compared to small molar volume. Molar volume (Figure 5) of the investigated ionic liquids matrices shows the same profile of the molar refractivity (Figure 3). It is important to

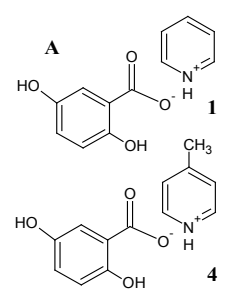

(2)<smiles>Cc1cccc[n+]1C(=O)c1cc(O)ccc1O</smiles><smiles>Cc1cc[nH+]cc1OC(=O)c1cc(O)ccc1O</smiles><smiles>CC=CCO</smiles><smiles>O=C(O)c1cc(O)ccc1O</smiles><smiles>CC=CCO</smiles><smiles>O=C(Oc1ccc(O)cc1C(=O)Oc1ccc(O)cc1)c1cc(O)ccc1O</smiles><smiles>O=C([O-])c1cc(O)ccc1O</smiles>

Figure 1: Chemical structure of DHB-ILMs (series 1), (a) hydrophobic pyridinium, (b) hydrophilic pyridinium and (c) diazinium.

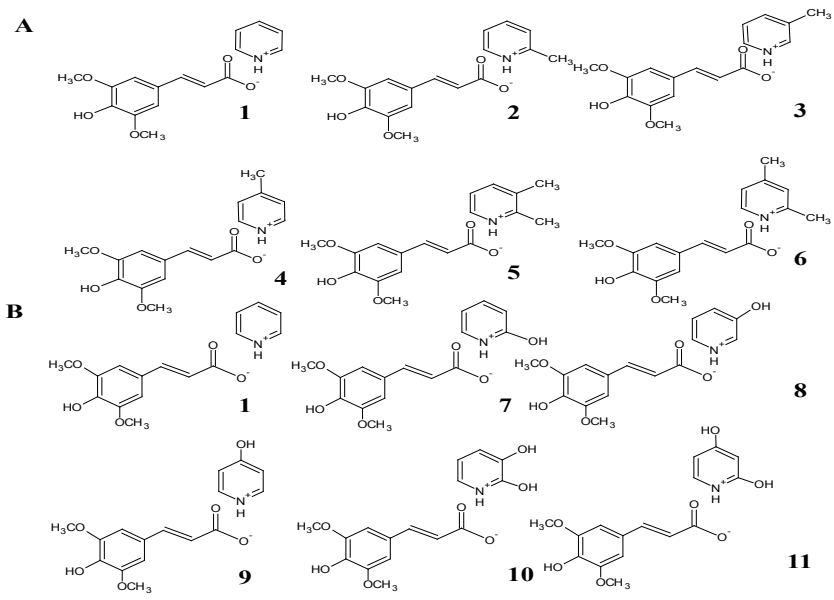

Figure 2: Chemical structure of SA-ILMs (series 2), (a) hydrophobic pyridinium and (b) hydrophilic pyridinium.

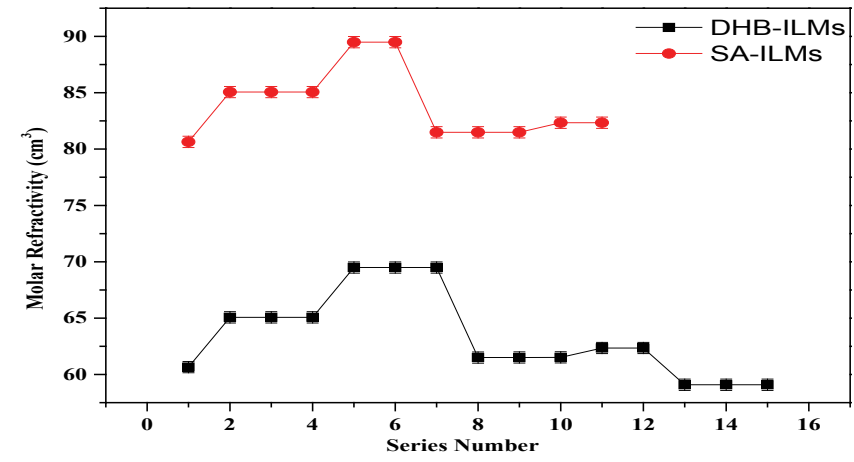

Figure 3: Molar refractivity of DHB-ILMs and SA-ILMs. 
Citation: Abdelhamid HN (2016) Physicochemical Properties of Proteomic lonic Liquids Matrices for MALDI-MS. J Data Mining Genomics Proteomics 7: 189. doi:10.4172/2153-0602.1000189

Page 3 of 6

\begin{tabular}{|c|c|c|c|c|c|c|c|c|}
\hline & 1 & 2 & 3 & 4 & 5 & 6 & \multicolumn{2}{|l|}{7} \\
\hline Molecular Formula & $\mathrm{C}_{12} \mathrm{H}_{11} \mathrm{NO}_{4}$ & $\mathrm{C}_{13} \mathrm{H}_{13} \mathrm{NO}_{4}$ & $\mathrm{C}_{13} \mathrm{H}_{13} \mathrm{NO}_{4}$ & $\mathrm{C}_{13} \mathrm{H}_{13} \mathrm{NO}_{4}$ & $\mathrm{C}_{14} \mathrm{H}_{15} \mathrm{NO}_{4}$ & $\mathrm{C}_{14} \mathrm{H}_{15} \mathrm{NO}_{4}$ & \multicolumn{2}{|l|}{$\mathrm{C}_{14} \mathrm{H}_{15} \mathrm{NO}_{4}$} \\
\hline Formula Weight & 233.22004 & 247.24662 & 247.24662 & 247.24662 & 261.2732 & 261.2732 & \multicolumn{2}{|l|}{261.2732} \\
\hline Compositions & $\begin{array}{l}\mathrm{C}(61.80 \%) \\
\mathrm{H}(4.75 \%) \\
\mathrm{N}(6.01 \%) \\
\mathrm{O}(27.44 \%)\end{array}$ & $\begin{array}{l}\text { C (63.15\%) } \\
\text { H (5.30\%) } \\
\text { N (5.67\%) } \\
O(25.88 \%)\end{array}$ & $\begin{array}{l}\text { C (63.15\%) } \\
\text { H (5.30\%) } \\
\text { N (5.67\%) } \\
\text { O (25.88\%) }\end{array}$ & $\begin{array}{l}\mathrm{C}(63.15 \%) \\
\mathrm{H}(5.30 \%) \\
\mathrm{N}(5.67 \%) \\
\mathrm{O}(25.88 \%)\end{array}$ & $\begin{array}{l}\text { C (64.36\%) } \\
\text { H }(5.79 \%) \\
\text { N }(5.36 \%) \\
O(24.49 \%)\end{array}$ & $\begin{array}{l}\text { C (64.36\%) } \\
\text { H (5.79\%) } \\
\text { N }(5.36 \%) \\
O(24.49 \%)\end{array}$ & \multicolumn{2}{|l|}{$\begin{array}{l}\text { C (64.36\%) } \\
\text { H }(5.79 \%) \\
\text { N (5.36\%) } \\
\text { O (24.49\%) }\end{array}$} \\
\hline Density, $\mathbf{g} / \mathrm{cm}^{3}$ & $1.31 \pm 0.1$ & $1.28 \pm 0.1$ & $1.28 \pm 0.1$ & $1.28 \pm 0.1$ & $1.25 \pm 0.1$ & $1.25 \pm 0.1$ & \multicolumn{2}{|l|}{$1.25 \pm 0.1$} \\
\hline RDBE & 8 & 8 & 8 & 8 & 8 & 8 & \multicolumn{2}{|l|}{8} \\
\hline Monoisotopic Mass & 233.06880 & 247.084458 & 247.084458 & 247.084458 & 261.100108 & 261.100108 & \multicolumn{2}{|l|}{261.100108} \\
\hline Nominal Mass & 233 & 247 & 247 & 247 & 261 & 261 & \multicolumn{2}{|l|}{261} \\
\hline Average Mass & 233.22 & 247.2466 & 247.2466 & 247.2466 & 261.2732 & 261.2732 & \multicolumn{2}{|l|}{261.2732} \\
\hline $\mathbf{M}^{+}$ & 233.06825 & 247.083909 & 247.083909 & 247.083909 & 261.099559 & 261.099559 & \multicolumn{2}{|l|}{261.099559} \\
\hline $\mathbf{M}^{-}$ & 233.06935 & 247.083909 & 247.2466 & 247.2466 & 247.2466 & 261.2732 & \multicolumn{2}{|l|}{261.2732} \\
\hline & 7 & 8 & 9 & 10 & 11 & 12 & 13 & 14 \\
\hline Molecular Formula & $\mathrm{C}_{12} \mathrm{H}_{11} \mathrm{NO}_{5}$ & $\mathrm{C}_{12} \mathrm{H}_{11} \mathrm{NO}_{5}$ & $\mathrm{C}_{12} \mathrm{H}_{11} \mathrm{NO}_{5}$ & $\mathrm{C}_{12} \mathrm{H}_{11} \mathrm{NO}_{6}$ & $\mathrm{C}_{12} \mathrm{H}_{11} \mathrm{NO}_{6}$ & $\mathrm{C}_{11} \mathrm{H}_{10} \mathrm{~N}_{2} \mathrm{O}_{4}$ & $\mathrm{C}_{11} \mathrm{H}_{10} \mathrm{~N}_{2} \mathrm{O}_{4}$ & $\mathrm{C}_{11} \mathrm{H}_{10} \mathrm{~N}_{2} \mathrm{O}_{4}$ \\
\hline Formula Weight & 249.21944 & 249.21944 & 249.21944 & 265.21884 & 265.21884 & 234.2081 & 234.2081 & 234.2081 \\
\hline Composition & $\begin{array}{l}\mathrm{C}(57.83 \%) \\
\mathrm{H}(4.45 \%) \\
\mathrm{N}(5.62 \%) \\
\mathrm{O}(32.10 \%)\end{array}$ & $\begin{array}{l}\text { C (57.83\%) } \\
\text { H (4.45\%) } \\
\text { N (5.62 \%) } \\
\text { O (32.10\%) }\end{array}$ & $\begin{array}{l}\text { C (57.83\%) } \\
\text { H (4.45\%) } \\
\text { N (5.62 \%) } \\
\text { O (32.10\%) }\end{array}$ & $\begin{array}{l}\text { C (54.34\%) } \\
\text { H (4.18\%) } \\
\text { N (5.28\%) } \\
\text { O (36.20\%) }\end{array}$ & $\begin{array}{l}\text { C (54.34\%) } \\
\text { H (4.18\%) } \\
\text { N (5.28\%) } \\
O(36.20 \%)\end{array}$ & $\begin{array}{l}\text { C (56.41\%) } \\
\text { H (4.30\%) } \\
\text { N (11.96\%) } \\
\mathrm{O}(27.33 \%)\end{array}$ & $\begin{array}{l}\mathrm{C}(56.41 \%) \\
\mathrm{H}(4.30 \%) \\
\mathrm{N}(11.96 \%) \\
\mathrm{O}(27.33 \%)\end{array}$ & $\begin{array}{l}\mathrm{C}(56.41 \%) \\
\mathrm{H}(4.30 \%) \\
\mathrm{N}(11.96 \%) \\
\mathrm{O}(27.33 \%)\end{array}$ \\
\hline Density, $\mathbf{g} / \mathbf{c m}^{3}$ & $1.42 \pm 0.1$ & $1.42 \pm 0.1$ & $1.42 \pm 0.1$ & $1.53 \pm 0.1$ & $1.53 \pm 0.1$ & $1.40 \pm 0.1$ & $1.40 \pm 0.1$ & $1.40 \pm 0.1$ \\
\hline RDBE & 8 & 8 & 8 & 8 & 8 & 8 & 8 & 8 \\
\hline Monoisotopic Mass & 249.063722 & 249.063722 & 249.063722 & 265.058637 & 265.058637 & 234.064057 & 234.064057 & 234.064057 \\
\hline Nominal Mass & 249 & 249 & 249 & 265 & 265 & 234 & 234 & 234 \\
\hline Average Mass & 249.2194 & 249.2194 & 249.2194 & 265.2188 & 265.2188 & 234.2081 & 234.2081 & 234.2081 \\
\hline $\mathbf{M}^{+}$ & 249.063174 & 249.063174 & 249.063174 & 265.058088 & 265.058088 & 234.063508 & 234.2081 & 234.2081 \\
\hline $\mathbf{M}^{-}$ & 249.064271 & 249.064271 & 249.064271 & 265.059186 & 265.059186 & 234.064605 & 234.063508 & 234.063508 \\
\hline
\end{tabular}

Table 1: Summary of the physical parameters for DHB-ILMs.

\begin{tabular}{|c|c|c|c|c|c|c|c|}
\hline & 1 & 2 & 3 & 4 & 5 & 6 & 7 \\
\hline Molecular Formula & $\mathrm{C}_{16} \mathrm{H}_{17} \mathrm{NO}_{5}$ & $\mathrm{C}_{17} \mathrm{H}_{19} \mathrm{NO}_{5}$ & $\mathrm{C}_{17} \mathrm{H}_{19} \mathrm{NO}_{5}$ & $\mathrm{C}_{17} \mathrm{H}_{19} \mathrm{NO}_{5}$ & $\mathrm{C}_{18} \mathrm{H}_{21} \mathrm{NO}_{5}$ & $\mathrm{C}_{18} \mathrm{H}_{21} \mathrm{NO}_{5}$ & $\mathrm{C}_{18} \mathrm{H}_{21} \mathrm{NO}_{5}$ \\
\hline Formula Weight & 303.30988 & 317.33646 & 317.33646 & 317.33646 & 331.36304 & 331.36304 & 331.36304 \\
\hline Compositions & $\begin{array}{l}\text { C (63.36\%) } \\
\text { H (5.65\%) } \\
\text { N (4.62\%) } \\
\text { O }(26.37 \%)\end{array}$ & $\begin{array}{l}\text { C }(64.34 \%) \\
H(6.03 \%) \\
N(4.41 \%) \\
O(25.21 \%)\end{array}$ & $\begin{array}{l}\mathrm{C}(64.34 \%) \\
\mathrm{H}(6.03 \%) \\
\mathrm{N}(4.41 \%) \\
\mathrm{O}(25.21 \%)\end{array}$ & $\begin{array}{l}\mathrm{C}(64.34 \%) \\
\mathrm{H}(6.03 \%) \\
\mathrm{N}(4.41 \%) \\
\mathrm{O}(25.21 \%)\end{array}$ & $\begin{array}{l}\mathrm{C}(65.24 \%) \\
\mathrm{H}(6.39 \%) \\
\mathrm{N}(4.23 \%) \\
\mathrm{O}(24.14 \%)\end{array}$ & $\begin{array}{l}\mathrm{C}(65.24 \%) \\
\mathrm{H}(6.39 \%) \\
\mathrm{N}(4.23 \%) \\
\mathrm{O}(24.14 \%)\end{array}$ & $\begin{array}{l}C(65.24 \%) \\
H(6.39 \%) \\
N(4.23 \%) \\
O(24.14 \%)\end{array}$ \\
\hline Density, $\mathbf{g} / \mathrm{cm}^{3}$ & $1.18 \pm 0.1$ & $1.16 \pm 0.1$ & $1.16 \pm 0.1$ & $1.16 \pm 0.1$ & $1.15 \pm 0.1$ & $1.15 \pm 0.1$ & $1.15 \pm 0.1$ \\
\hline RDBE & 9 & 9 & 9 & 9 & 9 & 9 & 9 \\
\hline Monoisotopic Mass (Da) & 303.11 & 317.126323 & 317.126323 & 317.126323 & 331.14 & 331.14 & 331.14 \\
\hline Nominal Mass & 303 & 317 & 317 & 317 & 331.36 & 331.36 & 331.36 \\
\hline Average Mass & 303.31 & 317.33 & 317.33 & 317.33 & 331.14 & 331.14 & 331.14 \\
\hline $\mathrm{M}^{+}$ & 303.11 & 317.33 & 317.33 & 317.33 & 331.14 & 331.14 & 331.14 \\
\hline \multirow[t]{2}{*}{ M- } & 303.11 & 317.13 & 317.13 & 317.13 & 331.14 & 331.14 & 331.14 \\
\hline & 8 & 9 & 10 & 11 & 12 & 13 & \\
\hline Molecular Formula & $\mathrm{C}_{16} \mathrm{H}_{17} \mathrm{NO}_{6}$ & $\mathrm{C}_{16} \mathrm{H}_{17} \mathrm{NO}_{6}$ & $\mathrm{C}_{16} \mathrm{H}_{17} \mathrm{NO}_{6}$ & $\mathrm{C}_{16} \mathrm{H}_{17} \mathrm{NO}_{7}$ & $\mathrm{C}_{16} \mathrm{H}_{17} \mathrm{NO}_{7}$ & $\mathrm{C}_{16} \mathrm{H}_{17} \mathrm{NO}_{7}$ & \\
\hline Formula Weight & 319.30928 & 319.30928 & 319.30928 & 335.30868 & 335.30868 & 335.30868 & \\
\hline Compositions & $\begin{array}{l}\mathrm{C}(60.18 \%) \\
\mathrm{H}(5.37 \%) \\
\mathrm{N}(4.39 \%) \\
\mathrm{O}(30.06 \%)\end{array}$ & $\begin{array}{l}\mathrm{C}(60.18 \%) \\
\mathrm{H}(5.37 \%) \\
\mathrm{N}(4.39 \%) \\
\mathrm{O}(30.06 \%)\end{array}$ & $\begin{array}{l}\mathrm{C}(60.18 \%) \\
\mathrm{H}(5.37 \%) \\
\mathrm{N}(4.39 \%) \\
\mathrm{O}(30.06 \%)\end{array}$ & $\begin{array}{l}\mathrm{C}(57.31 \%) \\
\mathrm{H}(5.11 \%) \\
\mathrm{N}(4.18 \%) \\
\mathrm{O}(33.40 \%)\end{array}$ & $\begin{array}{l}\mathrm{C}(57.31 \%) \\
\mathrm{H}(5.11 \%) \\
\mathrm{N}(4.18 \%) \\
\mathrm{O}(33.40 \%)\end{array}$ & $\begin{array}{l}\mathrm{C}(57.31 \%) \\
\mathrm{H}(5.11 \%) \\
\mathrm{N}(4.18 \%) \\
\mathrm{O}(33.40 \%)\end{array}$ & \\
\hline Density, $\mathbf{g} / \mathbf{c m}^{3}$ & $1.25 \pm 0.1$ & $1.25 \pm 0.1$ & $1.25 \pm 0.1$ & $1.33 \pm 0.1$ & $1.33 \pm 0.1$ & $1.33 \pm 0.1$ & \\
\hline RDBE & 9 & 9 & 9 & 9 & 9 & 9 & \\
\hline Monoisotopic Mass (Da) & 319.105587 & 319.105587 & 319.105587 & 335.100502 & 335.100502 & 335.100502 & \\
\hline Nominal Mass & 319 & 319 & 319 & 335 & 335 & 335 & \\
\hline Average Mass & 319.3093 & 319.3093 & 319.3093 & 335.3087 & 335.3087 & 335.3087 & \\
\hline $\mathbf{M}^{+}$ & 319.105 & 319.105 & 319.105 & 335.099953 & 335.099953 & 335.099953 & \\
\hline M- & 319.105 & 319.105 & 319.105 & 335.099953 & 335.099953 & 335.099953 & \\
\hline
\end{tabular}

Table 2: Summary of the physical parameters for SA-ILMs. 
stress that the molar volume is affected by the solvent properties. The interaction of ionic liquids 1-butyl-3-methylimidazolium bromide in water, methanol, and ethanol at $\mathrm{T}=(298.15$ to $318.15 \mathrm{~K})$ was reported [25]. Data indicate that the interactions of ionic liquids in water are stronger than in alcoholic solutions [25]. These results reinforce the influential effect of the analyte interaction. It is important to note that the values reported here refer to the changes of molar volume with the change of the cation structure. The hydrophobic pyridinium moieties show higher value compared to hydrophilic pyridinium moieties. Increase hydrophobicity $\left(2 \mathrm{CH}_{3}\right)$ show higher value compared to only $\mathrm{CH}_{3}$ group. The hydrophilic pyridinium moieties (with hydroxyl groups) show lower values. Both series of SA-ILMs and DHB-ILMS showed the same profile. The hydrophilic ionic liquids matrices have the same values of the pyridinium salts without any pendant groups, i.e., SA-ILMs or DHB-ILMs [1]. High molar volume is required to for gas phase formation. It is favorable for higher solvation efficiency. The molar volume of SA-ILMs indicates high ionic conductivity.

Index of refraction of the ionic liquids matrices was investigated for SA-ILMs and DHB-ILMs (Figure 6). The refractive index determines how much light is bent or refracted. In contrast with other parameters, DHB-ILMs showed higher index of refraction compared to SA-ILMs. The values increase from hydrophobic pyridinum cation compared to hydrophilic pyridinium cations. These data explain the lower performance of DHB-ILMs compared to SA-ILMs. The syntheses and refractive indices of some 1-alkyl-3-methyl imidazolium based ionic liquids containing polyhalide anions exhibit refractive indices between 1.6 and 2.23 [26]. For more than 17 room-temperature ionic liquids at various temperatures, refractive index and liquid density were calculated using Ab initio calculations [27]. They found that a highly linear correlation was found between the experimental refractive index and the predicted polarizability normalized in terms of the molar volume [27]. They proposed that the electronic polarization of the ionic liquids composing ions predominantly contributes to the refractive index of the room-temperature ionic liquids [27]. Two mathematical models (linear and non-linear) have been developed to estimate the refractive index values of 72 imidazolium-based ionic liquids using the electronic polarizability of their ions i.e cations and anions [28]. The impurities of ionic liquids matrices are very critical for ionic liquids matrices. Using the refractive indexes, it is easy to monitor the purities of ILMs.

Surface tension of DHB-ILMs and SA-ILMs were plotted in Figure 7. Surface tension reveals the cohesive forces between liquid molecules present at the surface and represents the quantification of force per unit length of free energy per unit area. It is an indirect but an effective methodology to access the intrinsic energies that is involved in the interactions between the ions. The importance and application of surface tension for ionic liquids were reviewed in Reference [29] in the period between 2001 and 2010. Typically, ionic liquids present surface tension values ranging from 20 dyne/cm up to 80 dyne $/ \mathrm{cm}$ [29]. The figure shows the surface tension values between 40-45 dyne/ $\mathrm{cm}$ for DHB-ILMs and 50-65 dyne/cm for SA-ILMs. The data reveal good agreement with typical ionic liquids. It is important to keep in our mind that most molecular solvents exhibit surface tensions at room temperature around or below $25 \mathrm{dyne} / \mathrm{cm}$. The figure reveals high surface tension for hydrophilic pyridinium cations compared to the hydrophobic pyridinium cations (Figure 7).

Density of DHB-ILMs and SA-ILMs were tabulated in Tables 1 and 2, respectively. The density values are in the range $1.15 \pm 0.1$ to

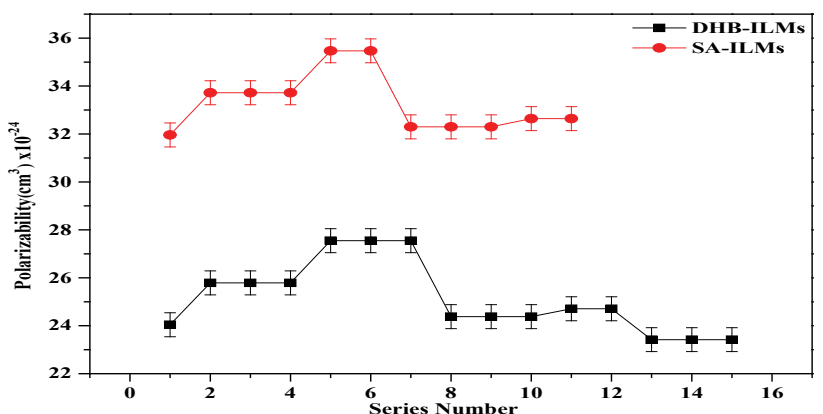

Figure 4: Polarizability of DHB-ILMs and SA-ILMs.

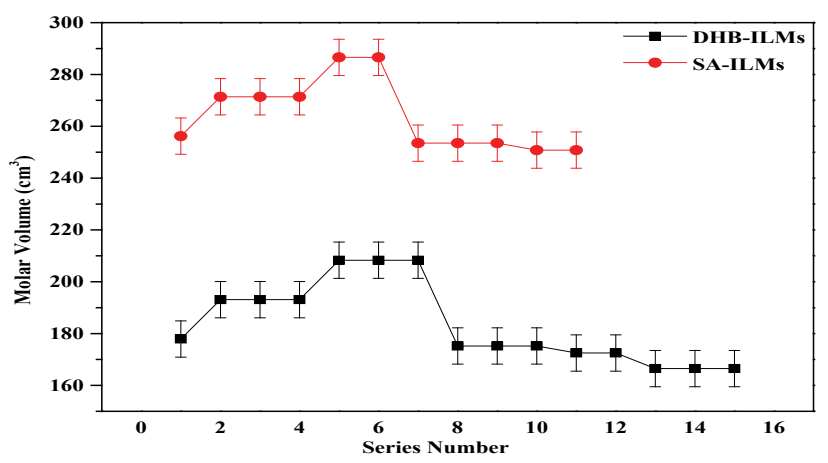

Figure 5: Molar volume of DHB-ILMs and SA-ILMs.

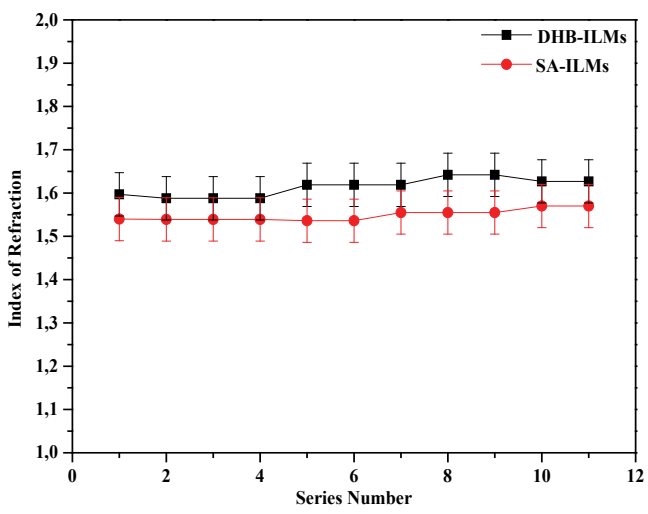

Figure 6: Index of refraction of DHB-ILMs and SA-ILMs.

$1.33 \pm 0.1 \mathrm{~g} / \mathrm{cm}^{3}$. The density and viscosity are related parameters. It was reported that increase in the alkyl chain length of the cation leads to a lower iconicity and increase viscosity [30]. This value depends on the molecular volume. It is important to mention that the transport properties of the ionic liquids depend on the cation moieties [31]. Because the high molecular weight of SA-ILMs compared to DHBILMs for the same pyridinium cation, the former showed high density over the latter.

Parachor quantities of ionic liquids matrices (Figure 8) were investigated. Parachor is a scientific quantity that can be defined as in equation 1. It gives a relation between three different parameters.

$$
\mathrm{P}=\gamma^{1 / 4} \mathrm{M} / \mathrm{d} \quad \text { (Equation 1) }
$$

Where, $\gamma, \mathrm{M}$ and $\mathrm{d}$ are the surface tension, the molar mass and the density, respectively. 


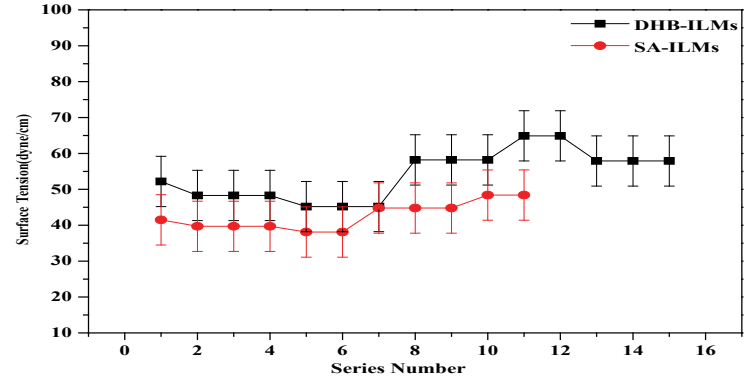

Figure 7: Surface tension of DHB-ILMs and SA-ILMs.

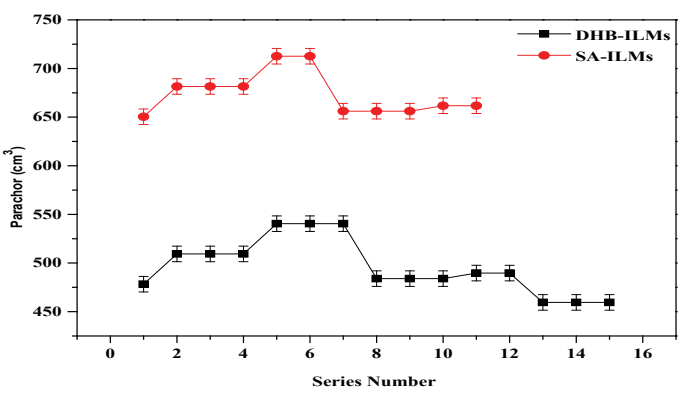

Figure 8: Parachor values of DHB-ILMs and SA-ILMs.

Parachor of ionic liquids was termed as ionic parachor [32]. Parachor values of SA based ionic liquids matrices are higher than DHB based ionic liquids matrices (Figure 8 ). The data reveal that the value of parachor is approximately equal. Figure 8 shows that the highest value was reported for dimethylpyridinium moieties for both series, i.e., DHB and SA. These values are important for the estimation of surface tension for pure ionic liquids. The pyridinium moieties with polar group such as hydroxyl groups show lower values compared to the pyridinium cations with methyl pendant groups. Diazinium moieties showed lower value compared to the pyridinium salts because the inductive effect of the heterocyclic rings (Figure 8).

Ionic liquids matrices (ILMs) have several distinctive properties compared to the conventional organic matrices. They have high performance for laser desorption/ionization process, offered soft ionization, showed no fragmentation, were free background and could serve for dual function, i.e., matrices and solvent for microextractions. Ionic liquids could serve as green solvent and have small vapor pressure. Thus, they are eco-friendly and are human harmless. Ionic liquids matrices have low melting point, high solvation power, and have high stability for storage and under vacuum.

\section{Conclusion}

In the present study, the physicochemical properties of the solutions of some ionic liquids matrices containing the pyridinium cations with different groups have been investigated. The properties of the several binary systems of DHB-ILMs and SA-ILMs were determined. Different ILMs were investigated in order to compare the effects of using different organic matrices. Parameters such as molar refractivity, molar volume, Parachor, index of refraction, polarizability and surface tension were investigated. Data revealed that the organic base showed dramatic changes of the properties of ionic liquids matrices (ILMs). These changes could be evaluated through their physicochemical parameters of the ILMs. These parameters may be useful as guidelines for the design of ILMs with high spectrum quality. The use of this relatively simple calculation is promising to understand the performance of ionic liquids matrices for mass spectrometry techniques such as Matrix assisted laser desorption/ionization mass spectrometry (MALDI-MS), and electrospray ionization mass spectrometry (ESI-MS).

\section{Acknowledgement}

H.N. Abdelhamid is grateful to Assuit University and Higher Education ministry, Egypt for the support of this study.

\section{References}

1. Karas M, Bahr U (1986) Laser desorption mass spectrometry. TrAC Trends Anal Chem 5: 90-93

2. http://www.nobelprize.org/nobel_prizes/chemistry/laureates/2002/

3. Dreisewerd K (2014) Recent methodological advances in MALDI mass spectrometry. Anal Bioanal Chem 406: 9-10.

4. Nasser AH, Wu HF (2013) Furoic and mefenamic acids as new matrices for matrix assisted laser desorption/ionization-(MALDI)-mass spectrometry. Talanta 115: 442-450.

5. Abdelhamid HN, Bhaisare ML, Wu HF (2014) Ceria nanocubic-ultrasonication assisted dispersive liquid-liquid microextraction coupled with matrix assisted laser desorption/ionization mass spectrometry for pathogenic bacteria analysis. Talanta 120: 208-217.

6. Abdelhamid HN, Talib A, Wu HF (2015) Facile synthesis of water soluble silver ferrite $\left(\mathrm{AgFeO}_{2}\right)$ nanoparticles and their biological application as antibacterial agents. RSC 5: 34594-34602.

7. Abdelhamid HN, Talib A, Wu HF (2015) Correction: Facile synthesis of water soluble silver ferrite $\left(\mathrm{AgFeO}_{2}\right)$ nanoparticles and their biological application as antibacterial agents. RSC Adv 5: 39952-39953.

8. Abdelhamid HN, Wu BS, Wu HF (2014) Graphene coated silica applied for high ionization matrix assisted laser desorption/ionization mass spectrometry: A nove approach for environmental and biomolecule analysis. Talanta 126: 27-37.

9. Abdelhamid HN, Wu HF (2014) Ultrasensitive rapid and selective detection of mercury using graphene assisted laser desorption/ionization mass spectrometry. J Am Soc Mass Spectrom 25: 861-868.

10. Abdelhamid HN, Wu HF (2015) Synthesis of a highly dispersive sinapinic acid@ graphene oxide (SA@GO) and its applications as a novel surface assisted laser desorption/ionization mass spectrometry for proteomics and pathogenic bacteria biosensing. Analyst 140: 1555-1565.

11. Abdelhamid HN, Wu HF (2012) A method to detect metal-drug complexes and their interactions with pathogenic bacteria via graphene nanosheet assist laser desorption/ionization mass spectrometry and biosensors. Anal Chim Acta 751: 94-104.

12. Hua PYA, Manikandan M, Abdelhamid HN, Wu HF (2014) Graphene nanoflakes as an efficient ionizing matrix for MALDI-MS based lipidomics of cancer cells and cancer stem cells. J Mater Chem B 2: 7334-7343.

13. Wu HF, Gopal J, Abdelhamid HN, Hasan N (2012) Quantum dot applications endowing novelty to analytical proteomics. Proteomics 12: 19-20.

14. Berkenkamp S, Kirpekar F, Hillenkamp F (1998) Infrared MALDI mass spectrometry of large nucleic acids. Science 281: 260-262.

15. Domon B, Aebersold R (2006) Mass spectrometry and protein analysis Science 312: 212-217

16. Abdelhamid HN, Khan MS, Wu HF (2014) Design, characterization and applications of new ionic liquid matrices for multifunctional analysis of biomolecules: a novel strategy for pathogenic bacteria biosensing. Anal Chim Acta 823: $51-60$

17. Wu HF, Gopal J, Abdelhamid HN (2013) Synthesis and application of ionic liquid matrices (ILMs) for effective pathogenic bacteria analysis in matrix assisted laser desorption/ionization (MALDI-MS) Anal Chim Acta vol 767: 104-111.

18. Abdelhamid $\mathrm{HN}$ (2015) lonic liquids for mass spectrometry: matrices, separation and microextraction. TrAC Trends Anal Chem.

19. Keaveney ST, Harper JB, Croft AK (2015) Computational approaches to understanding reaction outcomes of organic processes in ionic liquids. RSC Adv 5: 35709-35729. 
Citation: Abdelhamid HN (2016) Physicochemical Properties of Proteomic lonic Liquids Matrices for MALDI-MS. J Data Mining Genomics Proteomics 7: 189. doi:10.4172/2153-0602.1000189

Page 6 of 6

20. Yan T, Wang Y, Knox C (2010) On the structure of ionic liquids: comparisons between electronically polarizable and nonpolarizable models I. J Phys Chem B 114: 6905-6921.

21. Spange S, Lungwitz R, Schade A (2014) Correlation of molecular structure and polarity of ionic liquids J Mol Liq 192: 137-143.

22. Schade, Behme N, Spange S (2014) Dipolarity versus polarizability and acidity versus basicity of ionic liquids as a function of their molecular structures Chemistry 20: 2232-2243.

23. Yan T, Burnham CJ, Popolo DMG, Voth GA (2004) Molecular Dynamics Simulation of lonic Liquids: The Effect of Electronic Polarizability. J Phys Chem B 108: 11877-11881.

24. Yan T, Wang Y, Knox C (2010) On the dynamics of ionic liquids: comparisons between electronically polarizable and nonpolarizable models II. J Phys Chem B 114: 6886-6904.

25. Moattar MTZ, Shekaari H (2005) Apparent molar volume and isentropic compressibility of ionic liquid 1-butyl-3-methylimidazolium bromide in water, methanol, and ethanol at $\mathrm{T}=(298.15$ to 318.15) K. J Chem Thermodyn 37: 1029-1035.

26. Deetlefs M, Shara M, Kenneth R (2005) Seddon, Ionic Liquids III A: Fundamentals, Progress, Challenges, and Opportunities. Washington, DC: American Chemical Society 901.
27. Seki S, Tsuzuki S, Hayamizu K, Umebayashi Y, Serizawa N, et al. (2012) Comprehensive Refractive Index Property for Room-Temperature lonic Liquids J. Chem. Eng. Data 57: 2211-2216.

28. Rodriguez PD, Cancilla JC, Plechkova NV, Matute G, Seddon KR, et al.(2014) Estimation of the refractive indices of imidazolium-based ionic liquids using their polarisability values. Phys Chem Chem Phys 16: 128-134.

29. Tariq M, Freire MG, Saramago B, Coutinho JAP, Lopes JNC et al. (2012) Surface tension of ionic liquids and ionic liquid solutions. Chem Soc Rev 41: 2829-868.

30. Chiappe C, Sanzone A, Mendola D, Castiglione F, Famulari F, et al. (2013) Pyrazolium- versus imidazolium-based ionic liquids: structure, dynamics and physicochemical properties. J Phys Chem B 117: 668-676.

31. Tong J, Ma X, Kong YX, Chen Y, Guan W, et al. (2012) lonic parachor and its application II. Ionic liquid homologues of 1-alkyl-3-methylimidazolium propionate [C(n)mim] [Pro] $(n=2-6)$. J Phys Chem B 116: 5971-5976.

32. Lemraski EG, Zobeydi R (2014) Applying parachor method to the prediction of ionic liquids surface tension based on modified group contribution. J Mol Liq 193: 204-209. 